\title{
Neoscytalidium dimidiatum un raro agente de onicomicosis no dermatofítica en Chile
}

\author{
(Neoscytalidium dimidiatum a rare agent of non dermatophytic \\ onychomycosis in Chile)
}

Piontelli-Laforet, E. ${ }^{1}$, Vieille-Oyarzo, P. ${ }^{1 *}$

${ }^{1}$ Laboratorio Clínico Universidad de Valparaíso (UVCLIN). Cátedra de Micología, Escuela de Medicina, Universidad de Valparaíso.

*Autor para correspondencia: peggy.vieille@uv.cl

RECIBIDO: 23 de marzo 2020 APROBADO: 4 de noviembre 2020

DOI: $10.22370 /$ bolmicol.2020.35.2.2716

Palabras claves: Onicomicosis, Neoscytalidium dimidiatum.

Keywords: Onychomycosis, Neoscytalidium dimidiatum.

\section{RESUMEN}

El término de onicomicosis se emplea para describir las infecciones de las uñas causadas por diferentes grupos taxonómicos fúngicos ya sea filamentosos como levaduriformes. A pesar de que estas patologías son causadas en los vertebrados principalmente por integrantes de la Familia Artrodermatáceae (Onygenales), la micología médica aplicó para ellos la terminología más específica de dermatofitosis, por ser un grupo ecológico de mayor importancia y presencia clínica. Las dermatomicosis de piel y fanéreos, representan un conjunto de infecciones producidas por especies fúngicas distribuidas en ambientes diversos, capaces de crecer a temperaturas de $37^{\circ}$ y que actúan usualmente como patógenos oportunistas cuando existe generalmente un factor predisponente en el huésped. Se destaca la colonización en una uña de los pies en un hombre de 49 años por Neoscytalidium dimidiatum (Penz.) Crous \& Slippers, un reconocido fitopatógeno de rápido crecimiento, común en zonas tropicales y subtropicales, que presentó la capacidad de invadir tejidos queratinizados con un aspecto clínico indistinguible de los causadas por dermatofitos. Por la rara presencia de este hongo en nuestra zona geográfica (provincia de Valparaíso, Chile), se aportan los principales datos morfofisiológicos, taxonómicos y moleculares utilizados en su diagnóstico.

\begin{abstract}
The term onychomycosis is used to describe nail infections caused by different fungal taxonomic groups, either filamentous or yeast. Despite the fact that these pathologies are caused in vertebrates mainly by members of the Artrodermatáceae Family (Onygenales), medical mycology applied the more specific terminology of dermatophytosis for them, as it is an ecological group of greater importance and
\end{abstract}


Neoscytalidium dimidiatum un raro agente de onicomicosis no dermatofítica en Chile - Piontelli-Laforet, E.

clinical presence. Skin and pharynx dermatomycosis represent a set of infections produced by fungal species distributed in diverse environments, capable of growing at temperatures of $37^{\circ}$ and that usually act as opportunistic pathogens when there is a predisposing factor in the host. The colonization on a toenail in a 49-year-old man by Nesoscytalidium dimidiatum is highlighted (Penz.) Crous \& Slippers, a recognized fastgrowing phytopathogen, common in tropical and subtropical areas, which presented the ability to invade keratinized tissues with a clinical appearance indistinguishable from those caused by dermatophytes. Due to the rare presence of this fungus in our geographical area (Valparaíso province, Chile), the main morphophysiological, taxonomic and molecular data used in its identification are provided.

\section{INTRODUCCIÓN}

En general las onicomicosis no dermatofíticas en el país, se producen por hongos filamentosos o levaduriformes, que actúan principalmente a nivel de las uñas de los pies o manos, como los integrantes de los géneros Fusarium, Scopopulariopsis y Aspergillus, entre otros (Piontelli \& Toro 1987; 1888 Zaror \& Moreno 1995: Rodrigo Cruz et al., 2011).

En la mayoría de los casos los hongos considerados fuera de los dermatofitos actúan como oportunistas por la ausencia de queratinasas (con algunas excepciones como Fusarium solani y Neoscytalidium dimidiatum) por lo que dependen de otras condiciones, como un trauma previo, alteraciones anatómicas, la infección con- conjunta con un dermatofito o bacteria, alteraciones circulatorias especialmente en los hombres mayores de 60 años o debido deficiencias inmunes (Scher RK.et al. 2013, Bunyaratavej S, et al. 2015).

Las especies de Neoscytalidium (antiguamente Scytalidium), son hongos filamentosos que pertenecen a los Ascomycetes que integran un grupo heterogéneo y polifilético cuyas características particulares se conocen colectivamente como hongos dematiáceos o mohos negros, por producir hifas melanizadas oscuras que se distribuyen en el medio ambiente de regiones tropicales y subtropicales cálidas y se conocen principalmente por ser fitopatógenos [Cursi, IB. et al. 2011; Machuart et al. 2013). Por lo tanto, asociados principalmente con plantas y árboles frutales, pero también al suelo (De Hoog, G S. et al. 2004). N. dimidiatum, es un hongo dematiáceo productor de queratinas y se considera por ende como un patógeno primario en onicomicosis (Ramirez et al. (2017), que causa principalmente infecciones cutáneas, subcutáneas, corneales y el compromiso de órganos internos (Elewski, B. E. (1996); Alvarez, M. I. et al. (2004). Se han descrito casos de piel y uñas por $N$. dimidiatum en pacientes que provienen de África, Asia $\mathrm{y}$ muchos países de Latinoamérica, pero también en algunas zonas endémicas del sudeste asiático, donde las infecciones por $N$. dimidiatum son más significativas que las causadas por dermatofitos. (Ungpakorn, R. (2005); Lacroix C, et al. (2008); Cursi IB et al. (2011); Ranawaka, RR. (2012). Como la presencia de este hongo se encuentra en el suelo, la madera y los restos de plantas en descomposición, la infección humana ocurre principalmente después de una implantación traumática (Escobar, M.L \& Carmona-Fonseca, J. 2003). N. dimidiatum, se distingue solamente algunas veces de los dermatofitos por su aspecto característico sinuoso e hifal irregular en la microscopía directa de muestras cutáneas, pero principalmente por sus colonias de rápido crecimiento y su sensibilidad a la cicloheximida (Farr, D.F. et al. 2005; Arenas R, 2014). Clínicamente, los cuadros de onicomicosis por $N$. dimidiatum son indistinguibles de otras infecciones micóticas ungueales, aunque con frecuencia pueden presentar melanoniquia debido a la melanina del microorganismo (Alvarez, M.I, et al. 2004). Una situación que no se presentó en nuestro caso. 
Neoscytalidium dimidiatum un raro agente de onicomicosis no dermatofítica en Chile - Piontelli-Laforet, E.

\section{Reseña histórica taxonómica}

La primera presencia de este hongo en una micosis de las uñas en nuestra casuística merece algunos alcances por su variada historia taxonómica en el tiempo. En 1933, el micólogo británico Dr. Rolland Marshall describió un hongo asexual artroconidial que llamó Hendersonula toruloidea, responsable de causar la enfermedad en ciruelas, albaricoques y manzanos en Egipto (Nattras, 1933). En ese momento, reconoció que los cultivos de esporas individuales del hongo producían dos "formas" en cultivo: una forma micelial que se parecía a los miembros del género Torula con cadenas fragmentadas de artroconidios, y una forma picnidial caracterizada por la producción de esporas elipsoidales verdosas en pequeños sacos (Sutton BC. \& Dyko BJ 1989). El nombre $H$. toruloidea se aplicó a la última forma picnidial (Sutton BC. \& Dyko BJ. 1989). Otros investigadores compararon la forma de Torula con Torula dimidiata descrita por Otto Penzig en 1882, nombre conocido durante más de 50 años. En 1989 Sutton y Dyko crearon el género Nattrassia para acomodar a $H$. toruloidea y aplicaron el nombre Scytalidium dimidiatum al sinanamorfo micelial. También incluyeron en el nuevo género Nattrassia a Dothiorella mangiferae, que se convirtió en Nattrassia mangiferae, muy estrechamente relacionada y que prácticamente no se distingue de la forma picnidial original de Nattrass. Farr et al. (2005), reconocieron que ambos estados eran formas asexuales afiliadas al género Fusicoccum, un anamorfo de, Botryosphaeria. Propusieron entonces la transferencia de Scytalidium dimidiatum al género Fusicoccum como $F$. dimidiatum. Una reevaluación de la familia Botryosphaeriaceae por Crous et al. (2006), concluyó que el género Fusicoccum era polifilético, y crearon un nuevo género, Neoscytalidium para acomodar el hongo de Nattrass. Por separado erigieron el género Neofusicoccum para acomodar Nattrassia mangiferae (Sutton BC, \& Dyko BJ 1989; Crous et al. 2006) interpretando que $N$. dimidiatum es el nombre correcto para esta especie. La genética molecular generó una controversia significativa en su taxonomía y por lo tanto un aumento de sus sinónimos en el tiempo y en la literatura.

Neoscytalidium dimidiatum (Penz.) Crous \& Slippers,comb. nov. MycoBank MB500869

Sinónimo básico.: Torula dimidiata Penz., Michelia 2: 466.1882 (hifomicete sinanamorfo).

- $\equiv$ Scytalidium dimidiatum (Penz.) B. Sutton \& Dyko, Mycol. Res.93: 484. 1989.

- = Scytalidium hyalinum C.K. Campb. \& J.L. Mulder, Sabouraudia 15: 163 (1977)

- $\equiv$ Fusicoccum dimidiatum (Penz.) D.F. Farr, Mycologia 97: 740.2005.

- = Hendersonula toruloidea Nattrass, Trans. Brit. Mycol. Soc. 18:197. 1933 (coelomycete sinanamorfo).

= Neoscytalidium hyalinum (C.K. Campb. \& J.L. Mulder) A.J.L. Phillips, J.Z. Groenew. \& Crous, (2013). Studies in Mycology 76: 148

\section{CASO CLÍNICO}

Paciente masculino, 49 años, enviado por el dermatólogo para una toma de muestra de una aparente micosis por dermatofitos en el borde de una uña (cuarto ortejo pie derecho) de un año o más de evolución. Clínicamente se presentó como una lesión subungueal lateral / distal y paroniquia, acompañada de distrofia de la uña por engrosamiento de esta y asociada a una coloración amarillenta. El paciente no presentaba lesiones interdigitales ni en las plantas de los pies ni en palmas o uñas de las manos. Se efectuaron los raspados subungueales de la uña afectada, con bisturí estéril, colocando parte de éstos sobre un portaobjeto y agregando unas gotas de $\mathrm{KOH}$ al 20\% y un cubreobjeto, observándose a las 2 horas. El examen directo del raspado del material subungueal reveló la presencia de micelio fino septado, hialino con cierto aspecto toruloide en un extremo y buena semejanza a bajos aumentos con lo observado normalmente frente a la presencia de un dermatofito (Fig. 1A recuadro). 
Neoscytalidium dimidiatum un raro agente de onicomicosis no dermatofítica en Chile - Piontelli-Laforet, E.
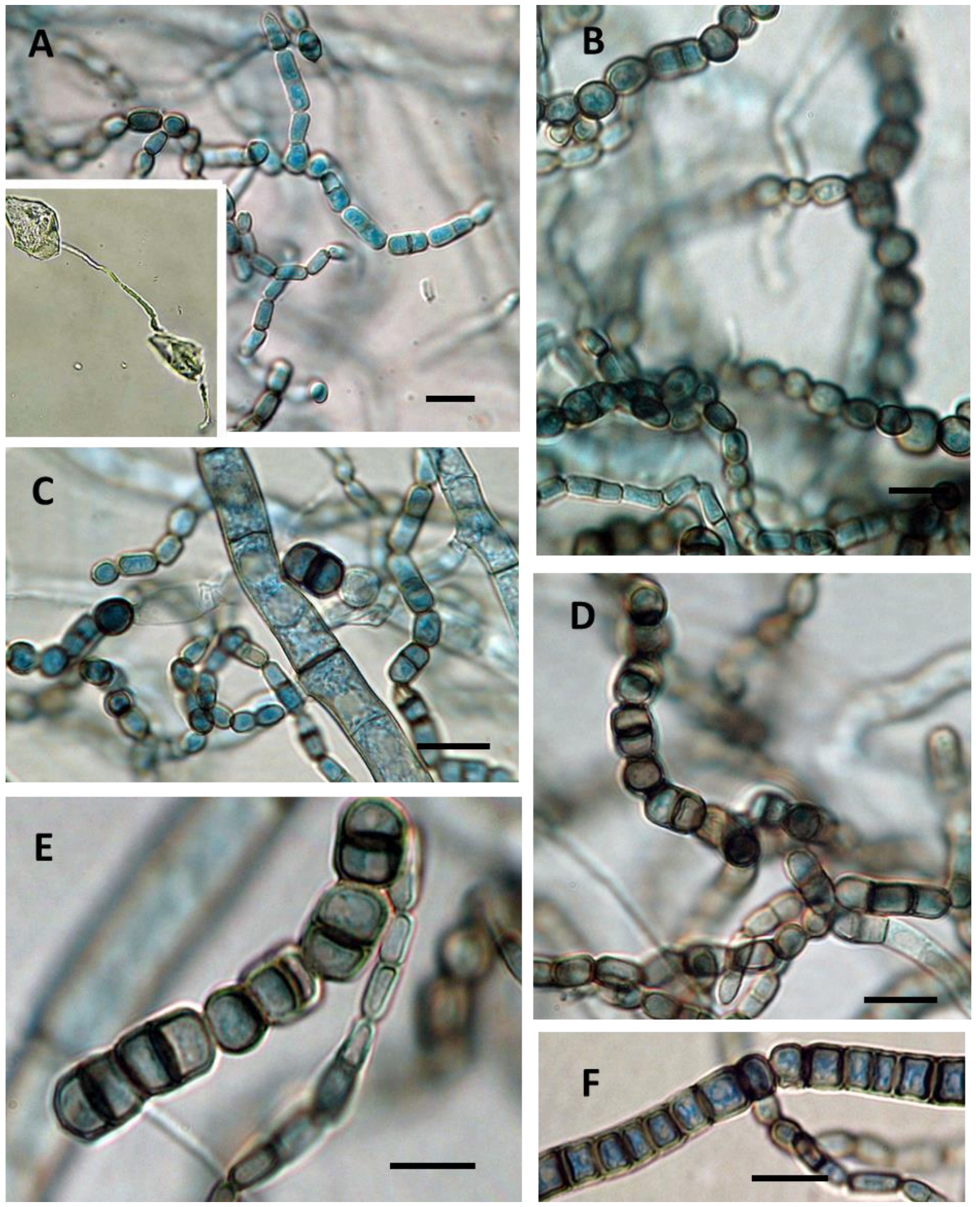

Figura 1. A-F. Micromorfología de Neoscytalidium dimidiatum. A. Hifas jóvenes desarticuladas en artroconidios hialinos o dematiáceos, cilíndricos y elípticos (en el recuadro un trozo de hifa hialina en el directo con KOH). B.D.F Artroconidios en cadenas de diferentes formas, color y septación. C. Artroconidios y dos hifas de diferente ancho. E. Artroconidios en forma de barril con extremos redondeados, gruesa pared y septo negro. Barras $10 \mu \mathrm{m}$. 
Neoscytalidium dimidiatum un raro agente de onicomicosis no dermatofítica en Chile - Piontelli-Laforet, E.

\section{Cultivo y Morfología macro-microscópica}

El cultivo del raspado de las uñas se realizó en 2 tubos de agar inclinado de Sabouraud al $10 \%$ y 2 tubos de agar Lactrimel, ambos con Cloranfenicol $(250 \mathrm{mg} / \mathrm{L})$. cultivándose a $25^{\circ} \mathrm{C}$ y $37^{\circ} \mathrm{C}$ por 14 días. Llamó la atención el rápido crecimiento de las colonias en los 4 tubos entre los 3 y 5 días en ambas temperaturas, al inicio con aspecto algodonoso, de color blanco grisáceo que fue ennegreciendo con el paso del tiempo. La semejanza de las colonias en ambos medios (más reducidas en tamaño a $37^{\circ} \mathrm{C}$ ), nos hizo pensar en una contaminación con algún hongo dematiáceo, sin embargo, al repetirse las siembras de las escamas, obtuvimos los mismos resultados, los que confirmaron el diagnóstico de onicomicosis no dermatofítica, basándonos en los criterios de English (1974). Es necesario considerar que no todos los exámenes directos de este hongo fuliginoso evidencian su pigmentación, como en nuestro caso, llevando a confusión la observación de un micelio hialino con el cultivo de un hongo negro (Gómez-Sáenz, A \& Araiza-Santibáñez, J. 2000).

Para una buena observación morfológica, las muestras se cultivaron en placas de Petri con agar avena con cloranfenicol en oscuridad por 8 días a $25^{\circ} \mathrm{C}$, creciendo rápidamente después de 48-72 h de incubación, presentando un micelio abundante de aspecto lanoso con hifas septadas, ramificadas, hialinas a subhialinas a marrón oscuro negruzco en el tiempo que varían de 2,5 hasta $9 \mu \mathrm{m}$ de ancho. El micelio se expandió rápidamente cubriendo casi los $9 \mathrm{~cm}$ de la placa al cuarto día, solevantado y de aspecto lanoso. El reverso de la colonia a los 8 días presentó un color grisáceo a negro intenso. Las características microscópicas en portaobjetos empleando ácido láctico $(60 \%)$ con azul de algodón, permitieron la observación de cadenas pulverulentas de artroconidios secos, lisos, de paredes gruesas, hialinos cuando en formación a café en el tiempo, de forma circular, oval o cilíndrica, con finales redondos o truncados con 1 o a veces 2 septos, de diferentes medidas en general, entre los 3,5-5 x 6-11 $\mu \mathrm{m}$, producidos por fragmentación holotálica de hifas indiferenciadas (Fig. 1A-F) Se obtuvieron colo-nias más reducidas a $37^{\circ} \mathrm{C}$, pero con las mismas características morfológicas. En base a su micromorfología y los resultados moleculares que se describen, el aislado se identificó como Neoscytalidium dimidiatum. Después de 4 semanas de cultivo, no se obtuvo la formación de su otro sinanamorfo picnidial. En agar Lactrimel y Sabouraud 10, empleados en nuestros cultivos para dermatofitos, también permitieron apreciar los detalles morfológicos básicos para su reconocimiento.

\section{Análisis molecular}

La extracción del ADN genómico se obtuvo por protocolo manual con CTAB (Cold Spring Harb. Protoc.2009). Por PCR convencional, se amplificó la región ITS usando cebadores universales ITS1 (5'-TCCGTAGGTGAACCT TGCGG-3') e ITS4 (5'-TCCTCCGCTTATTG ATATGC-3'). El producto de PCR obtenido fue secuenciado en ambas direcciones con los partidores antes señalados. La secuencia ITS resultante (GenBank ${ }^{\circ}$ XXXXXX) fue alineada junto a otras del género Neoscytalidium y especies relacionadas, usando la versión online de MAFFT 7.4 (Katoh et al. 2019) con estrategia automática y configuración predeterminada. El análisis filogenético se llevó a cabo usando inferencia bayesiana con el software MrBayes v3.1.2 (Huelsenbeck y Ronquist 2001), seleccionado el modelo de evolución GTRGAMMA y proporción de sitios invariantes. Se llevaron a cabo dos análisis MCMC independientes de 10.000.000 de generaciones, y con muestreo de un árbol cada 1.000 generaciones, empezando con un árbol al azar y utilizando 4 cadenas. Los primeros 2.500 árboles fueron descartados como burn-in y los restantes se combinaron para encontrar la probabilidad a posteriori (Figura 2). 
Neoscytalidium dimidiatum un raro agente de onicomicosis no dermatofítica en Chile - Piontelli-Laforet, E.

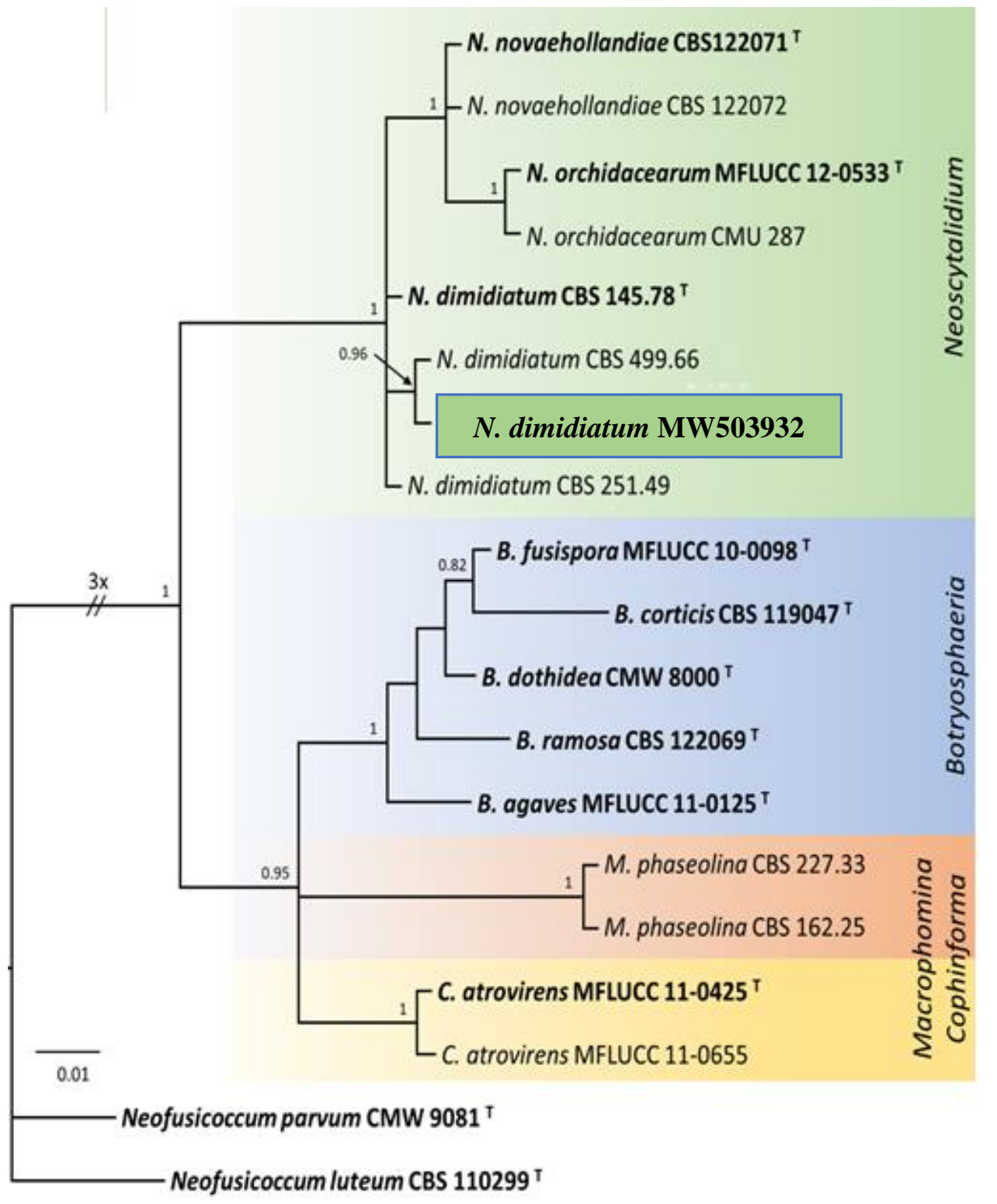

Figura 2. Árbol consenso (50\% majority-rule) de 7.500 árboles resultantes del análisis bayesiano para la región ITS del ADN ribosomal. Las probabilidades posteriores $\geq 0.8$ son indicadas sobre los nodos. El árbol fue enraizado en Neofusicoccum luteum. T: exType.

\section{DISCUSIÓN}

N. dimidiatum, es un saprotrofo del suelo y un potencial fitopatógeno, causante de enfermedades en vegetales leñosos (Hay, R, 1984). Por su termotolerancia $\left(42^{\mathrm{a}} \mathrm{C}\right.$ temp. máxima) puede causar lesiones oportunistas y superficiales en humanos ya sea en uñas, zonas palmoplantar y regiones interdigitales. Este hongo que fue aislado primariamente por Gentle \& Evans
(1970) desde uñas humanas, también ha causado infecciones sistémicas, que en algunos casos han sido previas a lesiones crónicas existentes de la piel o las uñas, lo que puede indicar un potencial reservorio de estos microorganismos en pacientes inmunosuprimidos o no (Hay, R, 2002; Elinav et al, 2009, Ikram et al, 2009; Garinet, S. et al, 2015). Las informaciones referentes a compromisos sistémicos son limitadas y generalmente asociadas al sistema Nervioso 
Neoscytalidium dimidiatum un raro agente de onicomicosis no dermatofítica en Chile - Piontelli-Laforet, E.

Central, pulmones, trasplantes de órganos y los ojos (Elinav H., et al. 2009; Garinet et al, 2005). A pesar que no es un dermatofito, actúa como tal en piel y uñas en humanos, pero realmente es más conocido causando lesiones en árboles frutales (Elinav, $\mathrm{H}$ et al, 2009). Si bien es cierto que los dermatofitos son la principal causa de onicomicosis en todo el mundo (Relloso, S. et al. (2012); Tsunemy, Y et al. (2014); Verrier, J.; Monod, M.(2017), la identificación de agentes etiológicos no dermatofitos son bastante comunes en onicomicosis por el creciente número de casos reportados en la literatura durante los 2 últimos decenios, una situación que ha obligado al micólogo médico a una constante ampliación de su aprendizaje taxonómico por tratarse de especies o grupos diferentes llevándolo hacia un camino a veces de inconsistencias diagnósticas per el solo empleo de datos morfológicos, o debido a la mezcla de 2 agentes involucrados como un dermatofito que no pudo crecer en los cultivos debido a su lentitud de desarrollo frente a un competidor que crece con mayor rapidez (Camilo A. MoralesCardona, et al. 2014). Gupta et al. (2000), describieron los principales puntos utilizados para el diagnóstico de onicomicosis no dermatofítica, destacando su morfofisiología mediante 2 muestras sucesivas o más si fuere necesario y su estudio detallado, que incluso necesita a veces la ayuda de expertos en ciertos grupos no asociados al orden o familias de los Onygenales. Actualmente la biología molecular es la que puede definir en forma precisa el hongo invasor. El aumento en la frecuencia de aislamiento de los mohos no dermatofitos en países cálidos incluyendo nuestra zona mediterránea de Viña del Mar( Chile), pueden explicarse por varios motivos tales como: el aumento de la esperanza de vida de poblaciones susceptibles como los ancianos y los inmunodeprimidos, los cambios sociales y culturales resultantes de la migración, la práctica deportiva más general, la natación, el uso de calzado oclusivo, los animales de compañía, el turismo, entre tantas otras causas (Escobar, M.L \& Carmona-Fonseca, J. 2003; Nascimento
Pontarelli L, 2005). Se conoce que los micelios no dermatofíticos no solo pueden invadir las uñas en el hombre, sino también los tejidos más profundos adyacentes e incluso diseminarse, sobre todo en pacientes con compromiso inmune, donde la literatura describe formas clínicas diversas que incluyen abscesos del sistema nervioso central, endoftalmitis, sinusitis, osteomielitis, micetoma e incluso sepsis. (Tan, Darrell, et al, (2008); Bunyaratavej S, et al. 2015). Aunque se han reportado aparentemente pocos casos de enfermedad diseminada por $N$. dimidiatum, como en trasplante renal, pulmonar o cardiaco, trauma, diabetes y cirrosis, así como el uso de corticosteroides durante tiempo prolongados. En un estudio clínico de 5 casos en pacientes con compromiso inmune, 3 de estos casos presentaban onicomicosis por Neoscytalidium, donde la mortalidad de estos pacientes puede alcanzar hasta un 50\% (Garinet et al. 2005). La literatura reconoce dos variantes de esta especie: una hialina ( $N$. hyalinum) y otra dematiácea ( $N$. dimidiatum). Ambas formas en sinonimia por sus semejanzas clínicas, morfológicas antigénicas y moleculares. Sin embargo, la primera, solo se diferencia por el color. Además, la forma hialina no se ha logrado aislar del ambiente y en general su hallazgo significa infección (Salas Campos et al. (2009). Nos llamó la atención que nuestro paciente en estudio no había salido en más de 20 años del país, sin embargo, en un comentario posterior mencionó a su madre como gran viajera incluyendo países tropicales. La pérdida de contacto del paciente posterior al diagnóstico, no permitió una información más completa de su anamnesis, en especial sobre su trabajo y actividades y el posible éxito del tratamiento recibido.

En la actualidad no existe un tratamiento establecido que demuestre efectividad verdadera frente a estos casos de onicomicosis, por $N$. dimidiatum (Machouart M. et al. 2013). El hongo es frecuentemente resistente in vivo a pesar que los test de susceptibilidad in vitro muestran una baja concentración inhibitoria [MICs] (Lacroix, C. et al. 2008; Madrid H. et al. 
Neoscytalidium dimidiatum un raro agente de onicomicosis no dermatofítica en Chile - Piontelli-Laforet, E.

2009). En las infecciones superficiales los tratamientos orales y tópicos clásicos frente a los dermatofitos son a menudo inefectivos frente a $N$. dimidiatum (griseofulvina, ketoconazol, itraconazol), posiblemente debido a la producción de melanina (Madrid, H. et al. 2009). La erradicación de las micosis se ha obtenido últimamente con el uso sistémico de los azoles (voriconazole, itraconazole, posaconazol) o la amphotericina B, y en la mayoría de los casos, la curación necesita un tiempo prolongado $\mathrm{y}$ a menudo son necesarias combinaciones de drogas (Madrid, H. et al. 2009; Grupta et al. 2012 (2012); Cursi, I.B., et al. 2013; Camilia. MoralsCardona et al. 2014; Gómez-Sáen, A \& AraizaSantibáñez Javier 2020). N. dimidiatum es inhibido in vitro por la ciclohexamida contenida en el medio de cultivo Micobiotic agar, empleados en muchos laboratorios, el cual permite el crecimiento y reconocimiento de los dermatofitos, por lo que es recomendable siempre inocular la muestra en este y otro medios que no tenga cicloexamida, (Arenas R.\& Isa Isa R. 2002; Salcedo I. et al. 2013).

En nuestra casuística que abarca más de 30 años, no hemos registrado este hongo en piel y fanéreos, ni en otras localizaciones clínicas. Su presencia en el país es posible debido a la constante migración humana y a las importaciones frutícolas exóticas. manteniendo quizás una baja presencia debido a factores edáficos o climáticos. Sin embargo, la importancia de este hallazgo es un reto para el diagnóstico micológico como en el éxito de su aparentemente complejo tratamiento curativo.

\section{AGRADECIMIENTOS}

Al Dr. Mario Zapata por las sugerencias aportadas en la metodología referente a la biología molecular del caso clínico.

\section{REFERENCIAS}

Alvarez, M. I., L. A. Gonzalez, and L. A. Castro. (2004). Onychomycosis in Cali, Colombia. Mycopathologia 158:181-186.

Arenas R. Isa Isa R. (2002). Onicomicosis por Scytalidium. Anamorfo de Natrassia mangifera. Primer caso en República Dominicana. Rev Dom Dermatol. 29(2):1921

Bunyaratavej. S, Prasertworonun N, Leeyaphan C et al. (2015). Distinct characteristics of Scytalidium dimidiatum and non-dermatophyte onychomycosis as compared with dermatophyte onychomycosis, Journal of Dermatology 42(3): 25862

Camilo A. Morales-Cardona, Martha C. Valbuena-Mesa, Zulma Alvarado and Andrea Solorzano-Amador (2014), Non-dermatophyte mould onychomycosis: a clinical and epidemiological study at a dermatology referral centre in Bogota,Colombia Mycoses, 57, 284-293

Crous W Pedro, Bernard Slippers, Michael J Wingfield, et al. (2006). Phylogenetic lineages in the Botryosphae-riaceae. Stud Mycol. 2006; 55: 235-53.

Cursi IB, Freitas LB, De Neves ML y Silva IC. (2011). Onycomychosis due to Scytalidium spp.: a clinical and epidemiologic study at a University Hospital in Rio de Janeiro, Brazil, An Bras Dermatol 86(4): 689-93.

De Hoog, G. S, J. Guarro, M. J. Figueras (2004). Atlas of clinical fungi. Fungal Biodiversity Inst. Univ. Rovira y Virgili

Elewski, B. E. (1996). Onychomycosis caused by Scytalidium dimidiatum. J. Am. Acad. Dermatol. $35: 336-33$

Elinav H, Izhar U, Benenson S, Admon D, HidalgoGrass C, Polacheck I, et al. (2009) Invasive Scytalidium dimidiatum Infection in an Immunocompetent Adult. J Clin Microbiol ; 47(4):125963.8. 
Neoscytalidium dimidiatum un raro agente de onicomicosis no dermatofítica en Chile - Piontelli-Laforet, E.

English MP. (1976). Nails and fungi. Br J Dermatol 94: 697-701

Escobar ML, Carmona-Fonseca J. (2003). Onychomycosis by common non dermatophyte moulds. Rev Iberoam Micol 20: 6-10. Spanish.

Farr, D. F., M. Elliott, A. Y. Rossman, and R. L. Edmonds. (2005). Fusicoccum arbuti sp. nov. causing cankers on Pacific madrone in western North America with notes on Fusicoccum dimidiatum, the correct name for Scytalidium dimidiatum and Nattrassia mangiferae. Mycologia 97:730-741. 7

Garinet S, Tourret J, Barete S et al. (2005). Invasive contaneous Neoscytalidium infections in renal transplant reciepients: a series of five cases, bmc Infections Dieseases 15: 535

Gentles JC, Evans EGV. 1970. Infection of the feet and nails with Hendersonula toruloidea. Sabouraudia $8: 72-75$

Gómez-Sáenz.A. y Javier Araiza-Santibáñez. (2020). Onicomicosis por Neoscytalidium dimidiatum: un examen directo atípico. Dermatología CMQ 18(1):45-47

Gupta AK, Jain HC, Lynde CW, MacDonald P, Cooper EA, Summerbell RC. (2000). Prevalence and epidemiology of onychomycosis in patients visiting physicians' offices: a multicenter Canadian survey of 15,000 patients. J Am Acad Dermatol 43: $244-8$.

Gupta AK, Drummond-Main C, Cooper EA et al. (2012), Systematic review of non-dermatophyte mold onychomycosis: diagnosis, clinical types, epidemiology, and treatment, J Am Acad Dermatol 66(3): 494-502

Hay R, Moore M. (1984). Clinical features of superficial fungal infections caused by Hendersonula toruloidea and Scytalidium hyalinum. Br J Dermatol 110: 677-83.

Hay RJ. (2002). Scytalidium infections. Curr. Opin. Infect. Dis. 15:99-100
Huelsenbeck JP, Ronquist F. (2001). MRBAYES: Bayesian inference of phylogenetic trees. Bioinformatics 17: 754-755.

Katoh Kazutaka, John Rozewicki, Kazunori D Yamada. (2019). MAFFT online service: multiple sequence alignment, interactive sequence choice and visualization. Brief Bioinform 19; 20(4):1160-1166

Ikram A, Hussain W, Satti ML, Wiqar MA. 2009. Invasive infection in a young immunocompetent soldier caused by Scytalidium dimidiatum. J. Coll. Physicians Surg. Pak. 19:64-66

Kwon-Chung, K.J; Bennett, J.E. (1992). Medical mycology. Philadelphia: Lea \& Febiger.

Lacroix C, Feuilhade de Chauvin M. (2008) In vitro activity of amphotericin B, itraconazole, voriconazole, posaconazole, caspofungin and terbinafine against Scytalidium dimidiatum an Scytalidium hyalinum clinical isolates. Journal of Antimicrobial Chemotherapy. 61, 835-837.

Machouart, M.; Menir, P.; Helenon, R.; Quist, D.; Desbois, N. (March 2013). "Scytalidium and scytalidiosis: What's new in 2012?". Journal de Mycologie Médicale / Journal of Medical Mycology. 23 (1): 40-46.

Madrid, H; Ruíz-Cendoya, M; Cano, J; Stchigel, A; Orofino, R; Guarro, J. (October 2009). "Genotyping and in vitro antifungal susceptibility of Neoscytalidium dimidiatum isolates from different origins". International Journal of Antimicrobial Agents. 34 (4): 351-4.

Nattrass, R.M. (1933). A new species of Hendersonula (H. toruloidea) on deciduous trees in Egypt. Transactions of the British Mycological Society. 18(3):189-198

Nascimento Pontarelli L, Hasse J, Galindo Cdo C, Coelho MP, Nappi BP, Ivo Dos Santos J. (2005). Case report onychomycosis by Scytalidium dimidiatum: Report of two cases in Santa Catarina,Brazil. Rev Inst Med. trop. (S. Paulo). 47(6):3513. 
Neoscytalidium dimidiatum un raro agente de onicomicosis no dermatofítica en Chile - Piontelli-Laforet, E.

Salcedo Inoa Noris \& Sandra Cabrera Castillo (2015). Scytalidium spp. en piel y uñas. Reporte de casos en Santo Domingo, República Dominicana, 2010-2014. Vitae EneroMarzo Nº61

Penzig, O. (1882). Funghi agrumicoli. Contribuzione allo studio dei funghi parassiti degli agrumi. Michelia. 2(8):385-508

Ramírez L, Gómez-Sáenz A, Vega DC y Arenas $\mathbf{R}$, (2017). Onicomicosis por mohos no dermatofitos. Una revisión, demq 15(3):184-94.

Ranawaka RR, De Silva N y Ragunathan RW. (2012)., Non-dermatophyte mold onychomycosis in Sri Lanka, Dermatol Online J. 18(1): 7.

Relloso S, Arechavala A, Guelfand L et al. (2012). Onychomycosis: multicentre epidemiological, clinical and mycological study]. Rev Iberoam Micol 2012; 29: 157-63.

Salas-Campos I, Gross-Martínez N y CarrilloDover P. (2009). Onicomicosis por hongos fuliginosos, Acta Méd Costarricense 2009; 51(4): 241-4

Salcedo Inoa N, Severino B, Cabrera Castillo S. (2013). Sinusitis micótica no invasiva y lesiones ungueales por Neoscytalidium dimidiatum. Comunicación de dos casos en República Dominicana. Rev. Académica Biomédica Digital, Venezuela. JulioSept., No.55

Sutton BC, Dyko BJ (1989). Revision of Hendersonula. Mycological Research 93: 466-488.

Scher RK, Rich P, Pariser D y Elewski B. (2013). The epidemiology, etiology, and pathophysiology of onychomycosis, Semin Cutan Med Surg 32 (2 Suppl 1): $2-4$.
Tan, Darrell H. S.; Sigler, Lynne; Gibas, Connie F. C.; Fong, Ignatius W. (January 2008). "Disseminated fungal infection in a renal transplant recipient involving Macrophomina phaseolina and Scytalidium dimidiatum: case report and review of taxonomic changes among medically important members of the Botryosphaeriaceae". Medical Mycology. 46 (3): 285-292

Tosti A, Piraccini BM, Lorenzi S. (2000). Onychomycosis caused by nondermatophytic molds: clinical features and response to treatment of 59 cases. J Am Acad Dermatol 42: 217-24

Tsunemi, Y.; Takehara, K.; Miura, Y.; Nakagami, G.; Sanada, H.; Kawashima, M. (2014). Screening for tinea unguium by Dermatophyte Test Strip. Br. J. Dermatol. 2014, 170, 328-331.

Ungpakorn, R. (2005). Mycoses in Thailand: current concerns. Nippon Ishinkin Gakkai Zasshi 46:81-86.

Velazquez-Flores H, Mendoza-Rodriguez C, Arenas R. (2005). Onicomicosis por Scytalidium sp. Revision de infecciones por Scytalidium (scytalidiosis) a proposito de un caso de melanoniquia]. Dermatologia Rev Mex2005; 49: 168-73. Spanish

Verrier, J.; Monod, M. (2017). Diagnosis of dermatophytosis using molecular biology. Mycopathologia 182,193-202

White TJ, Bruns T, Lee S, Taylor JW. (1990). Amplification and direct sequencing of fungal ribosomal RNA genes for phylogenetics. In Innis MA, Gelfand DH, Sninsky JJ, White TJ. (editors) PCR protocols: A Guide to Methods and Applications New York: Academic Press; pp 315324 